\title{
PROTECCIÓN CONSTITUCIONAL DE LA EDUCACIÓN EN PERÚ
}

\section{CONSTITUTIONAL PROTECTION OF EDUCATION IN PERU}

Elena Alvites ${ }^{1}$

Resumen: El objetivo del presente artículo es analizar cómo a partir de mandatos constitucionales objetivos ha sido posible, en el Perú, dotar de contenido subjetivo al derecho fundamental a la educación. Así, tras dar cuenta del marco normativo constitucional, se examina cómo a partir de la interpretación constitucional, conforme a los tratados internacionales, el Tribunal Constitucional ha desarrollado una línea jurisprudencial destinada a proteger este importante derecho fundamental.

Palabras clave: Derecho a la educación. Interpretación constitucional. Exigibilidad de derechos sociales. Tribunal constitucional.

\begin{abstract}
The objective of this article is to analyze how, based on objective constitutional mandates, it has been possible in Peru to provide subjective content to the fundamental right to education. Thus, after giving an account of the Peruvian constitutional legal framework, this article examines the jurisprudential line that the Peruvian Constitutional Court has developed to protect this important fundamental right, based on constitutional interpretation in accordance with international treaties.

Keywords: Right to education. Constitutional interpretation. Enforceability of social rights. Constitutional court.
\end{abstract}

\footnotetext{
1 Doctora en Derecho por la Universidad de Alicante y abogada por la Pontificia Universidad Católica del Perú; Profesora ordinaria asociada del Departamento de Derecho de la Pontificia Universidad Católica del Perú; Docente investigadora del Grupo de Investigación en Derecho Constitucional y Derechos Fundamentales, reconocido por el Vicerrectorado de Investigación de la Pontificia Universidad Católica del Perú; Avenida Universitaria, 1801, San Miguel de Lima 32, Peru; ealvites@ pucp.edu.pe
} 


\section{Contexto e introducción}

Actualmente, la educación básica en el Perú todavía no constituye un espacio en el que los niños, niñas y adolescentes del país desarrollen procesos de aprendizaje de calidad que aseguren su desarrollo integral como seres humanos, y que los prepare, en general, para la vida y el trabajo. Tal como exigen los artículos 13 y 14 de la Constitución Peruana, que coinciden con el Objetivo 4 de los Objetivos de Desarrollo Sostenible (ODS), que constituyen metas adoptadas por los Estados que forman parte del sistema de Naciones Unidas, para hacer frente a los desafíos ambientales, políticos, sociales y económicos que enfrenta el mundo actualmente (Programa de Naciones Unidas para el Desarrollo [PNUD], 2017, p. 3).

Dicho Objetivo 4 dispone los Estados parte de Naciones Unidas, garantice una evaluación inclusiva y equitativa de calidad, que promueva oportunidades de aprendizaje permanentes para todas las personas (PNUD, 2017, p. 7). Como parte de este objetivo, se ha previsto que para el año 2030 se asegure que las niñas, niños y adolescentes, sin discriminación alguna, accedan y permanezcan, al menos nueve años, en un sistema educativo de carácter público, obligatorio, gratuito y de calidad en donde adquieran aprendizajes pertinentes (Organización de las Naciones Unidas para la Educación, la Ciencia y la Cultura [UNESCO], 2017, pp. 11-12). En el Perú, para dar cuenta de los avances en relación con esta meta, el propio Ministerio de Educación (MINEDU) acude al indicador de tasa de conclusión de educación primaria y secundaria, cuya tendencia, ha sido positiva en los últimos quince años, tal como se aprecia en la figura adjunta (Ministerio de Educación [MINEDU], 2017, p. 1).

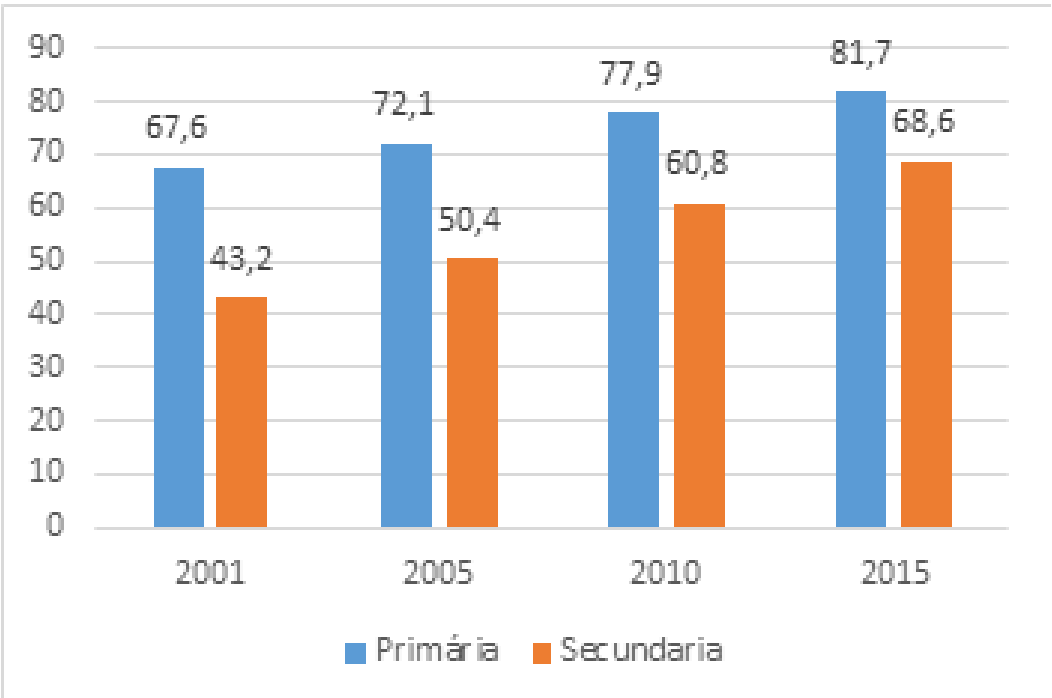

Figura 1. Tasa de conclusión primaria y secundaria (5 del total). Adaptada de "Edudatos, $N^{\circ} 28$. Objetivos de Desarrollo Sostenible (ODS): Aproximación al Objetivo 4," de Ministerio de Educación del Perú, 2017b. Disponible en: http://escale.minedu. gob.pe/c/document_library/get_file?uuid=187e3719-3b8b-4eab-af88-20c9e1e62e968groupId=10156

2 De acuerdo al artículo 17 de la Constitución del Perú los ciclos educativos obligatorio y, por ende, que conforman la educación básica en el Perú son inicial, primaria y secundaria. 
Sin embargo, dicha tasa de conclusión, referida en buena cuenta a la cobertura del sistema educativo peruano, debe ser leída en forma conjunta con la información sobre los logros de aprendizaje alcanzados. Cuyos resultados, como veremos, no son óptimos de cara a los mandatos constitucionales y al propio Objetivo 4 de los ODS.

En efecto, muestra de lo afirmado son los resultados de la Evaluación Censal de Estudiantes (ECE) que año a año lleva a cabo el MINEDU, en todas las instituciones educativas del país, públicas y privadas, que cuenten con más de cinco mil estudiantes. Esta evaluación estandarizada tiene como finalidad conocer qué y cuánto saben los estudiantes del segundo de primaria; pero en el año 2016 se extendió a los estudiantes cuarto año de primaria, y también a los aprendizajes, en materia de historia, geografía, economía, matemáticas y lectura, adquiridos por los estudiantes del segundo año de secundaria. En esta prueba, cada estudiante obtiene un determinado puntaje y en función del mismo, los estudiantes son ubicados en cuatro niveles de logro: i) Previo al inicio; ii) En inicio, iiI) En proceso y, iv) Satisfactorio (MINEDU, 2017, pp. 2-3).

Así, por ejemplo, en el caso de los logros alcanzados por los niños y niñas de segundo año de primaria, en los últimos diez años se aprecia que el nivel porcentual del logro satisfactorio ha aumentado paulatinamente; sin embargo, ese porcentaje no se acerca al 50\% tal como se aprecia en la siguiente figura:

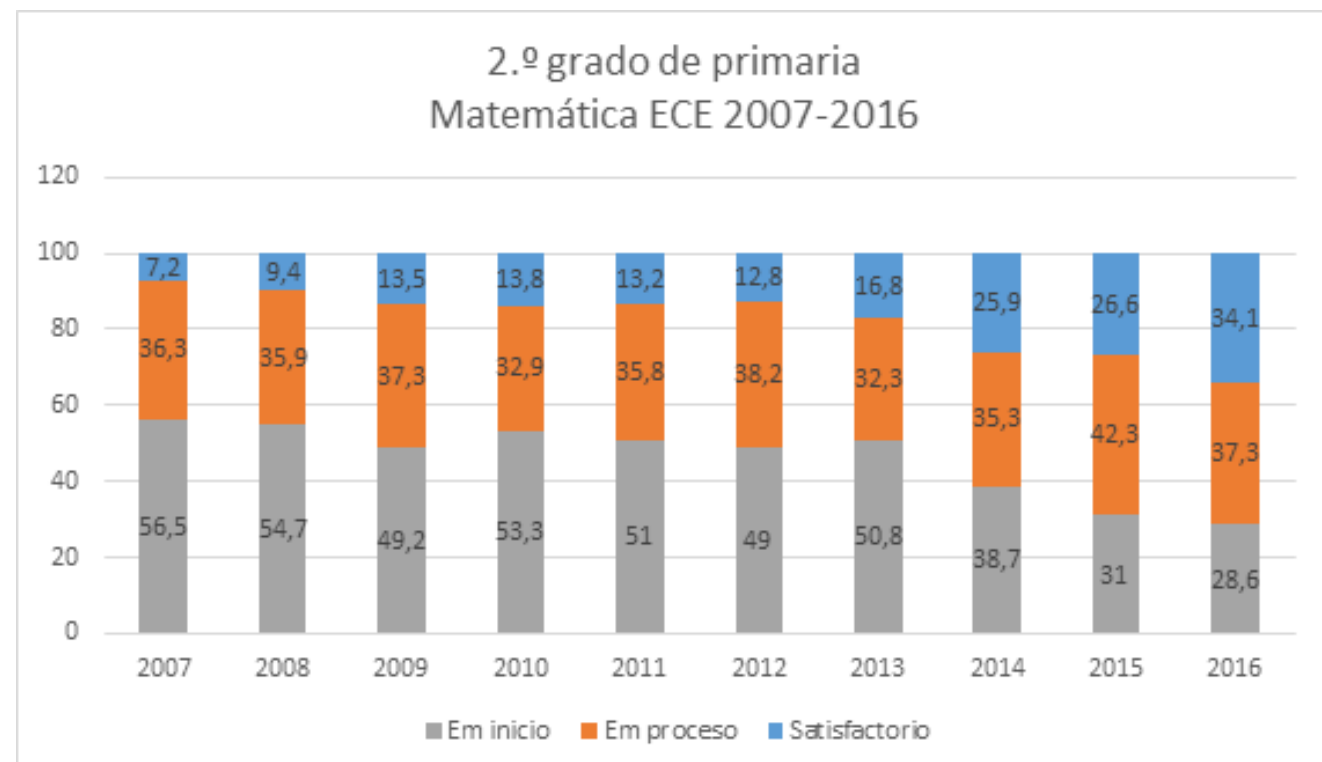

Figura 2. Matemática: resultados nacionales según niveles de logro en porcentaje. Adaptada de "Resultados de la Evaluación Censal de Estudiantes ECE 2016," de Ministerio de Educación del Perú, 2017c. Disponible en: http://umc.minedu.gob.pe/wp-content/uploads/2017/04/ECE-2016-presentaci\%C3\%B3n-de-resultados-web.pdf

Mejores son los resultados en los aprendizajes sobre lectura de los estudiantes de segundo año de educación primaria, en los que se aprecia una sostenida reducción del nivel en inicio, que es el nivel más bajo, y un crecimiento constante del porcentaje de estudiantes que se ubican en el nivel 
satisfactorio. Sin embargo, hasta el momento el porcentaje de nivel satisfactorio llega sólo al 46,4\% y, además, en el año 2016 hubo una disminución del 3,4\% en relación con los resultados del año anterior, tal como se puede verificar en la siguiente figura.

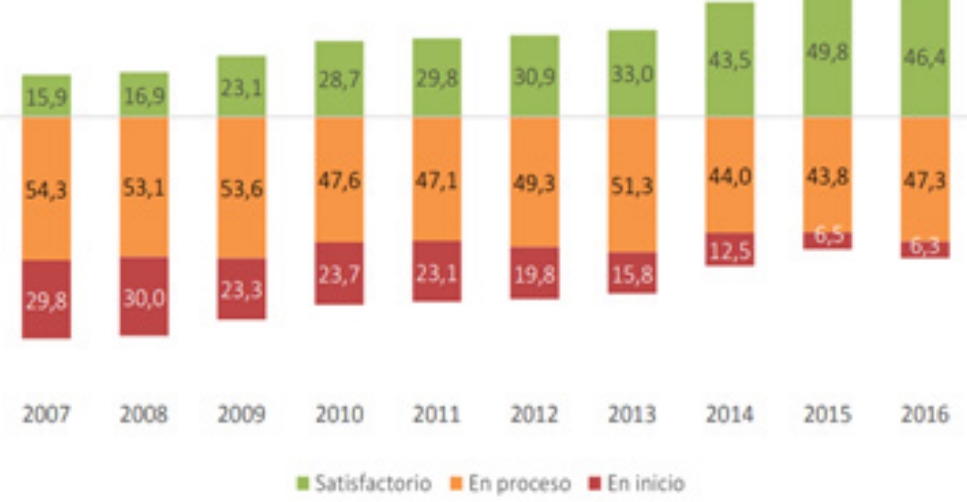

Figura 3. Lectura: resultados nacionales según niveles de logro en porcentaje. Adaptada de "Resultados de la Evaluación Censal de Estudiantes ECE 2016," de Ministerio de Educación del Perú, 2017c. Disponible en: http://umc.minedu.gob.pe/wp-content/ uploads/2017/04/ECE-2016-presentaci\%C3\%B3n-de-resultados-web.pdf

Sin embargo, las cifras generales que resultan más preocupantes son las que se recogieron en relación con los logros de los estudiantes de cuarto año de primaria y el segundo año de secundaria. En el caso del cuarto año de primaria, la ECE se aplicó por primera vez en el año 2016, y los porcentajes alcanzados en el nivel satisfactorio en matemáticas y lectura son sólo 25,2\% y 31,4\%, respectivamente. Adicionalmente, a diferencia de lo que sucede con los resultados del segundo año de primaria, para el cuarto año se aprecia que existe un porcentaje de estudiantes que se ubican en el nivel más bajo de la escala de la ECE. Su ubicación en ese nivel indica que los estudiantes ni siquiera han alcanzado los aprendizajes esperados para iniciar el cuarto grado de primaria (MINEDU, 2017, p. 7), tal como se verifica en la siguiente figura:

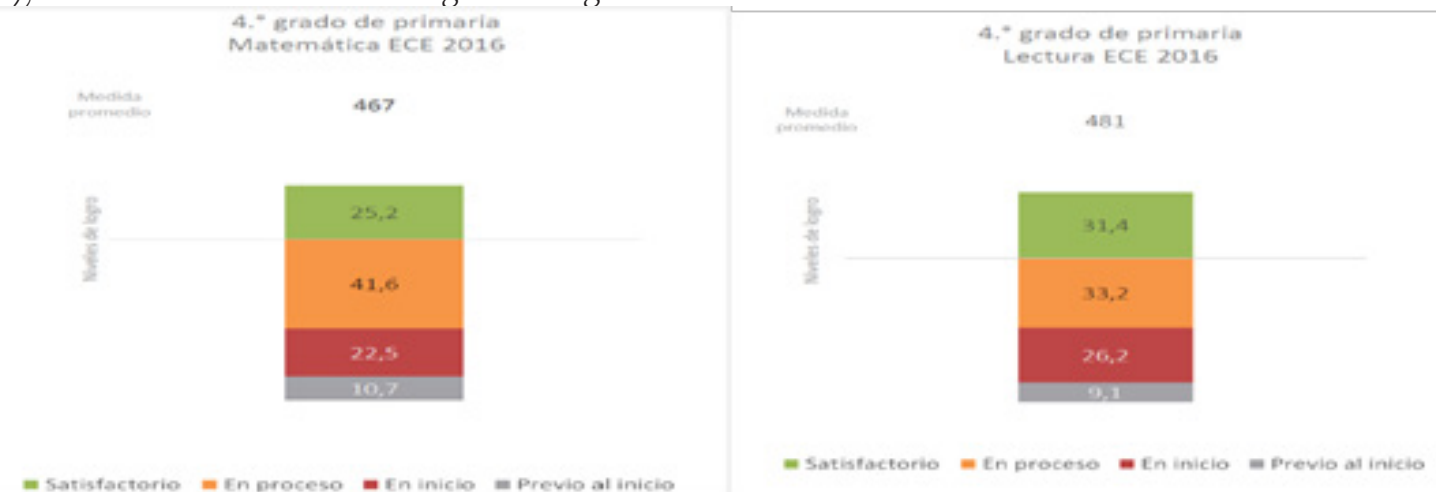

Figura 4. Resultados nacionales según medida promedio y niveles de logro en porcentaje: matemáticas y lectura. Adaptada de "Resultados de la Evaluación Censal de Estudiantes ECE 2016," de Ministerio de Educación del Perú, 2017c. Disponible en: http:// umc.minedu.gob.pe/wp-content/uploads/2017/04/ECE-2016-presentaci\%C3\%B3n-de-resultados-web.pdf 
En relación con los resultados del segundo año de educación secundaria, al que por primera vez se aplicó la ECE en campo de historia, geografía y economía, los resultados dan cuenta de que sólo un 15\%, como promedio nacional, alcanza el nivel satisfactorio, y más del 50\% de los estudiantes se ubican en los dos últimos niveles de logro, tal como se muestra en la siguiente figura.

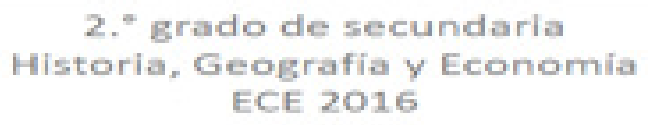

Nenctictas peromedis 500

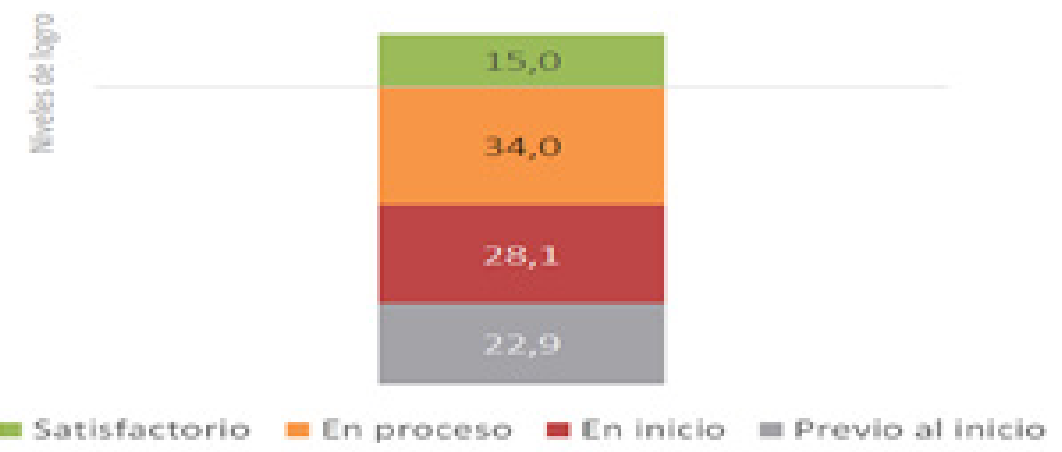

Figura 5. Historia, Geografía y Economía: resultados nacionales según medida promedio y niveles de logro en porcentajes. Adaptada de "Resultados de la Evaluación Censal de Estudiantes ECE 2016," de Ministerio de Educación del Perú, 2017c. Disponible en: http://umc.minedu.gob.pe/wp-content/uploads/2017/04/ECE-2016-presentaci\%C3\%B3n-de-resultados-web.pdf

Respecto a matemáticas y lectura, el desempeño de los estudiantes del segundo año de secundaria, si bien, presenta leves mejoras en relación con el año 2015, dado que hay un porcentaje mayor de estudiantes que se ubican en el nivel satisfactorio y en proceso. Empero, el porcentaje de estudiantes que se ubican en los últimos niveles de logro da cuenta de cómo los estudiantes, al avanzar su estancia en la educación básica, en mayor porcentaje no reflejan una tendencia constante de aprendizaje en matemáticas y lectura, tal como se visualiza en la siguiente figura. 


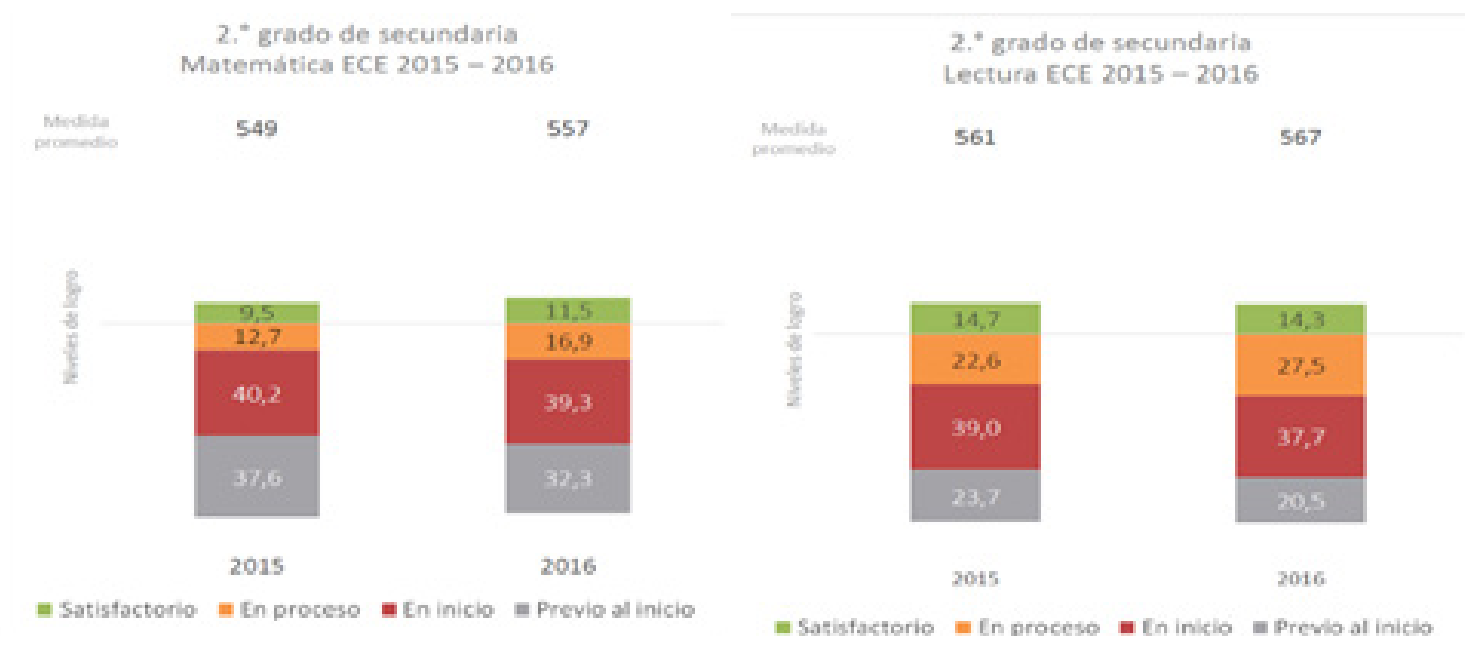

Figura 6. Resultados nacionales según medida promedio y niveles de logro en porcentaje: matemáticas y lectura. Adaptada de "Resultados de la Evaluación Censal de Estudiantes ECE 2016," de Ministerio de Educación del Perú, 2017c. Disponible en: http:// umc.minedu.gob.pe/wp-content/uploads/2017/04/ECE-2016-presentaci\%C3\%B3n-de-resultados-web.pdf

Las tasas de cobertura educativa, ejemplificada en las tasas de conclusión de primaria y secundaria, pero sobre todo los ambivalentes resultados de la ECE 2016, justifican la actualidad de la reflexión sobre el derecho fundamental a la educación, y constituye el escenario motivador para llevar a cabo nuestro objetivo de este trabajo; cual es, analizar cómo a partir de mandatos constitucionales de carácter objetivo, ha sido posible en el Perú afirmar el carácter fundamental del derecho a la educación y darle contenido subjetivo. En esa medida, sin perder de vista la relevancia que tiene la reflexión académica sobre la realidad educativa del país, el presente trabajo será de carácter dogmático, debido a que se elabora a partir del análisis documental de doctrina jurídica, textos normativos y la revisión crítica de la jurisprudencia del Tribunal Constitucional (TC).

En esa línea, en la primera parte del texto se dará cuenta del marco normativo constitucional sobre la educación previsto en la Constitución Peruana de 1993; en segundo lugar, presentar cómo a partir de la interpretación constitucional, conforme a los tratados internacionales sobre derechos humanos, el TC ha desarrollado una línea jurisprudencia destinada a proteger la dimensión subjetiva del derecho a la educación, sin dejar de evidenciar las obligaciones estatales.

La revisión de la línea jurisprudencia del TC se orientará, en tercer lugar, a sugerir algunos aportes para fortalecer dicha construcción jurisprudencial a partir de la tesis del doble carácter de los derechos fundamentales. Ello, considerando que la actual Constitución peruana de 1993, a diferencia de su antecesora la Constitución de $1979^{3}$ que reconocía el derecho fundamental a la educación, no contiene un dispositivo iusfundamental en el que expresamente se considere a la educación como derecho subjetivo de carácter fundamental, sino que incluye de dispositivos redactados como órdenes

\footnotetext{
3 Constitución de 1979. Artículo 21. El derecho a la educación y a la cultura es inherente a la persona humana. La educación tiene como fin el desarrollo integral de la personalidad. Se inspira en los principios de la democracia social. El Estado reconoce y garantiza la libertad de enseñanza.
} 
y permisiones; vale decir, como mandatos de protección que destacan las obligaciones que le corresponde cumplir al Estado y, de cierta forma, la dimensión objetiva o institucional de la educación.

\section{La protección constitucional de la educación}

La satisfacción del derecho a la educación constituye un presupuesto indispensable para la democracia, así como para la plena realización de los seres humanos y el ejercicio de otros derechos fundamentales; como sucede, por ejemplo, con el libre desenvolvimiento de la personalidad, las libertades de expresión e información, o los derechos políticos. De esta forma lo ha entendido el Comité de Derechos Económicos, Sociales y Culturales, al indicar que su satisfacción es un presupuesto para la superación de males que todavía subsisten en nuestra sociedad como la opresión contra la mujer, la pobreza, o la explotación de los niños, niñas o adolescentes (Comité de Derechos Económicos, Sociales y Culturales, 1999, párrafo, 1).

La Organización de las Naciones Unidas para la Educación, la Ciencia y la Cultura (UNESCO), reafirma tal valor de la educación, que además se incorpora como temática de los ODS, al señalar que se trata de un derecho fundamental y habilitador, porque permite aspirar a la "plena realización de la personalidad humana y promover el entendimiento mutuo, la tolerancia, la concordia y la paz"; además, como bien público, el principal responsable de su protección, respecto y realización es el Estado, aunque comparte dicha tarea con la sociedad (UNESCO, 2017, p. 8).

Estas afirmaciones sobre el derecho a la educación, como derecho social fundamental, son consistentes con su vinculación directa con las condiciones de existencia de las personas; pues, se orienta a la construcción de autonomía (Nery da Silva \& García Masson, 2015, p. 197) y a la satisfacción de necesidades básicas; por ende, su plena satisfacción debe modificar las estructuras económicas, sociales y culturales de una comunidad (Cascajo Castro, 1988, p. 24) para hacer más democrática. Se trata de un derecho fundamental que también se fundamenta en la dignidad humana y la igualdad de oportunidades, puesto que contribuye a alejar al ser humano de privaciones que lo ponen directamente con relación al daño o a graves sufrimientos como pueden ser la pobreza, la explotación o la discriminación (Añon Roig, 1994, p. 266; Häberle, 2002, p. 196).

En esa línea, en el Estado social y democrático, que es la fórmula política que adopta el Estado constitucional, la educación cumple funciones vinculadas al desarrollo de las personas, quienes van construyendo sus capacidades de manera que puedan auto determinarse y ejercer su libertad (Baldassarre, 2004, p. 150). La satisfacción del derecho a la educación, en esa medida, evidenciará el cumplimiento de tres funciones que, a nuestro juicio, cumplen los derechos sociales en los sistemas constitucionales, como son: (i) la función correctora del proceso social, al ampliar la eficacia de los derechos fundamentales de libertad, extendiendo su eficacia a un número mayor de individuos; (ii) la función liberadora, al complementar y dotar de mayor densidad a la libertad, y; (iii) la función igualadora, al posibilitar la realización de la igualdad material entre los seres humanos (Alvites, 2004, 
pp. 29-30). De esa forma, el derecho a la educación contribuye a densificar el concepto de libertad estrictamente jurídica para dar paso a la libertad fáctica como producto de la superación de los obstáculos que la realidad coloca al libre desarrollo de los individuos (Alexy, 1993, pp. 486 y ss.).

A pesar de la importancia del derecho a la educación, la Constitucional peruana de 1993, lo excluye formalmente del Capítulo I del Título I de la Constitución en el que se enumeran los derechos fundamentales de la persona; así, los mandatos constitucionales sobre la educación fueron incorporados en el Capítulo II del mismo Título I, denominado De los Derecho sociales y Económicos. De esta forma, se pretendió establecer una diferencia normativa entre los derechos sociales, como el derecho a la educación, y los considerados derechos fundamentales clásicos o de libertad que están reconocidos en el mencionado Capítulo I. Sin embargo, como se verá, tal distinción, tanto desde el punto de vista sustantivo o material como procesal, no tiene relevancia en lo que toca al carácter fundamental y eficacia normativa del derecho a la educación.

La concepción formal de los derechos fundamentales (Alexy, 2003, p. 21) que se habría buscado incorporar a la Constitución de 1993 es desvirtuada por el artículo $3^{\circ}$ de la misma Carta Fundamental que establece una norma de apertura al catálogo de derechos fundamentales (Häberle, 1991, pp. 114 y ss.) y viene a equiparar las categorías derechos fundamentales y derechos constitucionales (Castillo Córdova, 2005, p. 67). De esa forma, también lo ha sostenido el TC al señalar que

la enumeración de los derechos fundamentales previsto en la Constitución, y la cláusula de los derechos implícitos o no enumerados, da lugar a que en nuestro ordenamiento todos los derechos fundamentales sean a su vez derechos constitucionales, en tanto es la propia Constitución la que incorpora en el orden constitucional no sólo a los derechos expresamente contemplados en su texto, sino a todos aquellos que, de manera implícita, se deriven de los mismos principios y valores que sirvieron de base histórica y dogmática para el reconocimiento de los derechos fundamentales. (STC 1417-2005-AA-TC, E.J 4).

Lo dispuesto por el artículo $3^{\circ}$ de la Constitución, ${ }^{4}$ justifica normativamente la condición de derecho fundamental del derecho a la educación en el ordenamiento constitucional peruano, dada su vinculación directa con la dignidad humana, su aporte al libre desenvolvimiento de la personalidad y a la autonomía de las personas, pues resulta ser la condición para el ejercicio pleno de derechos y libertades (Kweitel \& Ceriani, 2006, p. 208). De igual modo, ya se ha indicado como la educación es un presupuesto importante para la consolidación de la democracia. Asimismo, cabe mencionar, que el derecho a la educación también es pasible de tutela urgente constitucional, a través del proceso de amparo, de acuerdo al artículo 200 de la Constitución y al artículo 37 del Código Procesal Constitucional que, en la relación de derechos en cuya defensa procede el proceso de amparo, incluye se encuentra el derecho a la educación. Esto se debe a que la Constitución recoge una tesis amplia

\footnotetext{
4 Constitución de 1993. Artículo 3.- La enumeración de los derechos establecidos en este capítulo no excluye los demás que la Constitución garantiza, ni otros de naturaleza análoga o que se fundan en la dignidad del hombre, o en los principios de soberanía del pueblo, del Estado democrático de derecho y de la forma republicana de gobierno.
} 
sobre la protección de los derechos fundamentales (Abad Yupanqui, 2008, p. 111), evidenciando la intrínseca relación que existen entre todos estos derechos, incluyendo a los derechos sociales.

No obstante, y como ya se adelantó, la Constitución de 1993 no explicita la fórmula "todas las personas tienen derecho a la educación." Ninguno de sus dispositivos que norman los diferentes aspectos de la educación fue redactado en clave de derecho subjetivo; ${ }^{5}$ vale decir, como una posición jurídica que pueda ser expresada como derechos de protección, de organización y procedimiento, o a prestaciones (Alexy, 1993, pp. 482). Las disposiciones constitucionales acentúan la dimensión institucional de la educación y destacan las obligaciones que le corresponde cumplir al Estado, tal como puede verse en el siguiente cuadro en el que, a partir de la redacción de los dispositivos constitucionales, se ha identificado los limitados mandatos formulados en la Constitución como derechos subjetivos, y aquellos otros que expresan las obligaciones del Estado:

\begin{tabular}{|c|c|}
\hline Constitución de 1993 - dispositivos constitucionales & $\begin{array}{l}\text { entificación de los principales mandatos norma- } \\
\text { vo }\end{array}$ \\
\hline $\begin{array}{l}\text { La educación tiene como finalidad el desarrollo integral de } \\
\text { persona humana. El Estado reconoce y garantiza la libertad } \\
\text { enseñanza. Los padres de familia tienen el deber de educar a su } \\
\text { hijos y el derecho de escoger los centros de educación y de part } \\
\text { cipar en el proceso educativo. }\end{array}$ & $\begin{array}{l}\text { Estado debe asegurar que proceso educativo debe garan- } \\
\text { tice el desarrollo integral de la persona humana. } \\
\text { Libertad de enseñanza. } \\
\text { Obligación de los padres de educar a sus hijos. } \\
\text { Derecho de los padres de escoger el centro educativo de } \\
\text { sus hijos y de participar en el proceso de educativo. }\end{array}$ \\
\hline $\begin{array}{l}\text { Artículo 14.- Educación para la vida y el trabajo. Los me- } \\
\text { dios de comunicación social } \\
\text { La educación promueve el conocimiento, el aprendizaje y la } \\
\text { práctica de las humanidades, la ciencia, la técnica, las artes, la } \\
\text { educación física y el deporte. Prepara para la vida y el trabajo y } \\
\text { fomenta la solidaridad. } \\
\text { Es deber del Estado promover el desarrollo científico y tecnoló- } \\
\text { gico del país. } \\
\text { La formación ética y cívica y la enseñanza de la Constitución } \\
\text { y de los derechos humanos son obligatorias en todo el proceso } \\
\text { educativo civil o militar. La educación religiosa se imparte con } \\
\text { respeto a la libertad de las conciencias. } \\
\text { La enseñanza se imparte, en todos sus niveles, con sujeción a los } \\
\text { principios constitucionales y a los fines de la correspondiente } \\
\text { institución educativa. } \\
\text { Los medios de comunicación social deben colaborar con el Esta- } \\
\text { do en la educación y en la formación moral y cultural. }\end{array}$ & $\begin{array}{l}\text { Obligación del Estado de: } \\
\text { Asegurar que la educación promueva el conocimiento, } \\
\text { aprendizaje y práctica de diversos ámbitos del saber hu- } \\
\text { mano. } \\
\text { Asegurar que el proceso educativo fomente la solidari- } \\
\text { dad y preparare a las personas para desenvolverse en la } \\
\text { sociedad y el trabajo. } \\
\text { Asegurar que el proceso educativo incorporé de manera } \\
\text { obligatoria la enseñanza de la Constitución y los dere- } \\
\text { chos humanos. } \\
\text { Obligación del Estado de promover el desarrollo cientí- } \\
\text { fico y tecnológico. } \\
\text { Obligación de los medios de comunicación de colaborar } \\
\text { con la educación. }\end{array}$ \\
\hline
\end{tabular}

\footnotetext{
5 El derecho subjetivo alude a una posición o poder jurídico que se reconoce a un individuo y que, a la par, le otorga la posibilidad de actuar contra los obligados a su cumplimiento, los cuales pueden ser autoridades públicas o particulares. Al respecto, para la definición clásica de derecho subjetivo, acudimos al jurista austríaco Kelsen (1986, p. 148), quien señalaba que el derecho subjetivo se concretaba en la atribución, por parte de una norma, del poder jurídico de reclamar, mediante una acción, el cumplimiento de la obligación. Para Alexy (1993, p. 178), un derecho subjetivo debe ser entendido como una posición o relación jurídica dada en un ordenamiento jurídico. Por su parte, Arango (2001, p. 143), partiendo del concepto acuñado por Alexy, señala que un derecho subjetivo puede definirse como "la posición normativa de un sujeto, para la que es posible dar razones válidas y suficientes, y cuyo no reconocimiento injustificado le ocasiona un daño inminente a dicho sujeto".
} 


\begin{abstract}
Artículo 15.- Profesorado, carrera pública
El profesorado en la enseñanza oficial es carrera pública. La ley establece los requisitos para desempeñarse como director o profesor de un centro educativo, así como sus derechos y obligaciones. El Estado y la sociedad procuran su evaluación, capacitación, profesionalización y promoción permanentes.

El educando tiene derecho a una formación que respete su identidad, así como al buen trato psicológico y físico.

Toda persona, natural o jurídica, tiene el derecho de promover y conducir instituciones educativas y el de transferir la propiedad de éstas, conforme a ley.
\end{abstract}

\section{Artículo 16.- Descentralización del sistema educativo}

Tanto el sistema como el régimen educativo son descentralizados.

El Estado coordina la política educativa. Formula los lineamientos generales de los planes de estudios, así como los requisitos mínimos de la organización de los centros educativos.

Supervisa su cumplimiento y la calidad de la educación.

Es deber del Estado asegurar que nadie se vea impedido de recibir educación adecuada por razón de su situación económica o de limitaciones mentales o físicas.

Se da prioridad a la educación en la asignación de recursos ordinarios del Presupuesto de la República.

Artículo 17.- Obligatoriedad de la educación inicial, primaria y secundaria

La educación inicial, primaria y secundaria son obligatorias. En las instituciones del Estado, la educación es gratuita. En las universidades públicas el Estado garantiza el derecho a educarse gratuitamente a los alumnos que mantengan un rendimiento satisfactorio y no cuenten con los recursos económicos necesarios para cubrir los costos de educación.

Con el fin de garantizar la mayor pluralidad de la oferta educativa, y en favor de quienes no puedan sufragar su educación, la ley fija el modo de subvencionar la educación privada en cualquiera de sus modalidades, incluyendo la comunal y la cooperativa.

El Estado promueve la creación de centros de educación donde la población los requiera.

El Estado garantiza la erradicación del analfabetismo. Asimismo, fomenta la educación bilingüe e intercultural, según las características de cada zona. Preserva las diversas manifestaciones culturales y lingüísticas del país. Promueve la integración nacional. Figura 7. Constitución Política del Perú 1993
Obligaciones del Estado de implementar una carrera docente que contemple la profesionalización, la capacitación y la promoción de los docentes.

Derecho a acceder formación que respete la identidad cultural.

Derecho a recibir buen trato físico y psicológico en el proceso educativo.

Derecho a promover la creación y conducir instituciones educativas privadas.

Obligación de organizar el sistema educativo de forma descentralizada.

Obligación del formular y coordinar la política educativa en el marco de la descentralización, con tres niveles de gobierno.

Obligación de formular lineamientos generales, planes de estudio y requisitos sobre mínimos de la organización de centros educativos.

Asegurar el acceso al sistema educativo sin limitaciones de tipo económicas, físicas o mentales.

Supervisar la prestación y calidad del servicio educativo en todos los niveles.

Prioridad de la educación para la asignación de recursos presupuestales.

Obligatoriedad de la educación inicial, primaria y secundaria.

Obligación del Estado de:

Asegurar la gratuidad de la educación en las instituciones educativas del Estado.

Asegurar la pluralidad de la oferta educativa, a través de la promoción de la creación de centros educativos y subvenciones a la educación privada.

Erradicar el analfabetismo.

Asegurar la educación intercultural bilingüe, de acuerdo a las características de la población en las distintas zonas del país.

Preservar la diversidad cultural y lingüística, promover la integración nacional.

Ciertamente, lo que más destaca del articulado constitucional, es que se omite expresar las principales posiciones jurídicas subjetivas que suelen derivarse del derecho a la educación, como son: el derecho a acceder al servicio educativo sin discriminación alguna; el derecho a permanecer en el proceso educativo no debiendo ser arbitrariamente separado de las instituciones educativo, y; el derecho a que el servicio educativo brindado sea de calidad (Kweitel \& Ceriani, 2006, pp. 214-219; 
Landa Arroyo, 2017, pp. 166-167). No obstante, si es posible identificar algunos elementos que resultan imprescindibles en el régimen constitucional de la educación.

Así, resulta importante destacar que la Constitución reconozca que la finalidad de la educación es el desarrollo integral de la persona. Asimismo, se garantizar la libertad de enseñanza e identifica el deber de los padres de educar a sus hijos, y su derecho a participar del proceso educativo y escoger el centro educativo para ello. De esta forma, el artículo 13 de la Constitución contiene uno de los pocos dispositivos que reconoce algunas posiciones subjetivas que conforman el derecho a la educación, dando cuenta de la complejidad de dicho derecho, que no solo involucra una serie de prestaciones sino también de libertades (Castillo Córdova, 2004, pp. 73 y ss.). Asimismo, la Constitución expresa las diversas obligaciones estatales respecto al diseño e implementación de un sistema educativo que propicie el desarrollo de los seres humanos y los capacite para para participar en una sociedad libre y tolerante. Precisamente, es en atención a estas obligaciones que el Estado debe cumplir para con las personas, que cabe preguntarnos si de ellas es posible derivar verdaderos derechos subjetivos de carácter fundamental.

En el artículo 14 de la Constitución, se refirma el papel de la educación en el desarrollo de las personas y dispone cuál es el deber de los medios de comunicación con relación a la educación. También ordena que la educación promueva el conocimiento, el aprendizaje y la práctica de las humanidades, la ciencia, la técnica, las artes, la educación física y el deporte, y establece como deber del Estado promover el desarrollo científico y tecnológico del país. Asimismo, el artículo $16^{\circ}$ establece obligaciones que deberían tener especial incidencia en el diseño de políticas públicas, como es que el Estado está obligado a asegurar que nadie se vea impedido de recibir educación adecuada por razones de situación económica o limitaciones mentales o físicas, y que deba dar prioridad a la educación al momento de asignarle recursos en el presupuesto general de la república. La primera obligación está directamente vinculada al mandato de igualdad y no discriminación, previsto en el artículo 2.2 de la Constitución, mientras que la segunda está directamente vinculada a la necesidad de asegurar recursos financieros para la educación, pues sin ellos no sería viable política alguna (Nery da Silva \& García Masson, 2015, p. 205).

Por su parte, el artículo $17^{\circ}$ incorpora las tres garantías básicas de la educación como derecho fundamental subjetivo como son como: su carácter universal, obligatorio y gratuito en instituciones del Estado (Martínez De Pisón, 2003, p. 69). De la incorporación de estas tres garantías, ciertamente, se derivan una prohibición -no reclamar pago alguno en las instituciones educativas públicas-y también mandatos al Estado para que asegure cobertura y calidad del sistema educativo; es decir, para que se cumplan los elementos de disponibilidad y accesibilidad de la educación.

Precisamente, el TC, como veremos enseguida, a partir del complejo normativo conformado por las disposiciones objetivas sobre la finalidad del proceso educativo, las distintas obligaciones del Estado sobre el diseño, implementación y supervisión del sistema educativo, así como de la identificación del carácter obligatorio y gratuito de la educación, ha construido diversas posiciones 
jurídicas subjetivas que conforman el derecho fundamental a la educación. En los argumentos desarrollados por el TC, como enseguida veremos, el valor normativo de la Cuarta Disposición Final y Transitoria de la Constitución ${ }^{6}$ ha sido determinante, dado que la interpretación de los dispositivos constitucionales se ha realizado conforme a lo establecido en los tratados internacionales que el Perú ha ratificación. En particular, por lo regulado por el Pacto Internacional de Derechos Económicos, Sociales y Culturales, ${ }^{7}$ y por el Protocolo Adicional a la Convención Americana sobre Derechos Humanos en materia de Derechos Económicos, Sociales y Culturales, también denominado Pacto de San Salvador. ${ }^{8}$

\section{El Tribunal constitucional y el derecho a la educación}

Para el TC las funciones de carácter social que le corresponde cumplir al Estado social y democrático están relacionadas con la realización de los elementos o fines sociales que lo identifican como modelo de Estado, siendo el derecho a la educación una manifestación de ello. De esta forma, acudiendo de forma enunciativa a su jurisprudencia acerca del doble carácter de los derechos fundamentales (STC 3330-2004-AA/TC de, F. J. 9; STC 1757-2007-PA/TC, F.J 6 a), ha afirmado que los derechos sociales, como el derecho a la educación, además de ser un derecho subjetivo, son fines sociales que permiten identificar a una Estado como social y democrático. Asimismo, ha señalado que dichos derechos ingresan al catálogo de derechos fundamentales como una ampliación de los derechos fundamentales de autonomía y persiguiendo la misma finalidad de éstos; cual es garantizar la dignidad humana y la efectiva participación de la ciudadanía en el sistema democrático, sobre todo de aquellos sectores de la sociedad que padecen inseguridad materia (STC 4232-2004-AA/TC, FF. JJ 4-5).

En ese contexto, en varias oportunidades el TC se ha pronunciado sobre el contenido del derecho a la educación (STC 0052-2004-AA/TC, STC 0091-2005-PA/TC, STC 4232-2004-AA/TC, STC 10034-2005-PA/TC, STC 4646-2007-PA/TC, STC 1391-2007-PA/TC, STC 00025-2007-PI/TC, STC 01351-2012-PA/TC, STC 01423-2013-PA/TC), así como a los fines y principios del proceso educativo, y las distintas obligaciones que deben cumplir el Estado para garantizar la plena satisfacción del derecho a la educación. En las siguientes líneas veremos los aspectos más relevantes de la jurisprudencia del TC en esta materia.

\footnotetext{
6 Constitución Peruana 1993. Cuarta Disposición final y transitoria.- Interpretación de los derechos fundamentales. Las normas relativas a los derechos y a las libertades que la Constitución reconoce se interpretan de conformidad con la Declaración Universal de Derechos Humanos y con los tratados y acuerdos internacionales sobre las mismas materias ratificados por el Perú.

7 Este tratado internacional fue adoptado el 16 de diciembre de 1966 en el seno de Naciones Unidas y fue ratificado e incorporado al ordenamiento jurídico peruano el 28 de abril de 1978.

8 Este tratado internacional fue adoptado el 17 de noviembre de 1988 en el seno de la Organización de Estados Americanos y ratificado por el Estado peruano el 4 de junio de 1995.
} 


\subsection{El contenido del derecho a la educación}

El derecho a la educación ha sido considerado por el TC como un derecho fundamental de naturaleza compleja, cuyo contenido constitucionalmente protegido está determinado por: el acceso a una educación adecuada; la libertad de enseñanza; la libre elección del centro docente; el respeto a la libertad de conciencia de los estudiantes; el respeto a la identidad de los educandos; el buen trato psicológico y físico; la libertad de cátedra y; la libre creación de centros docentes y universitario (STC 0091-2005-PA/TC, F.J. 6).

Asimismo, a partir de los mandatos y obligaciones estatales recogidas en los artículos $13^{\circ}$, $14^{\circ}, 15^{\circ}$ y $16^{\circ}$ de la Constitución el TC ha derivado las principales facultades protegidas por el derecho fundamental a la educación; como son: "a) el acceder a la educación; b) la permanencia y el respecto a la dignidad del escolar; y c) la calidad de la educación." (STC N 4232-2004-AA/TC, FF. JJ 10 - 11; STC 4646-2007-PA/TC, F.J 15; STC 00025-2007-PI/TC F.J 20). De esa forma, a partir de los mandatos de protección derivados de la dimensión objetiva de dicha normas, el TC ha desprendido verdaderos derechos subjetivos (Böckenförde, 1993, pp. 114-115).

En el caso del acceso, el TC ha señalado que se garantiza tanto la cobertura educativa cuanto el acceso en sentido estricto, proscribiéndose los requisitos de admisibilidad a los centros educativos que contengan criterios discriminatorios. En efecto,

los centros escolares, tanto públicos como privados, deben proscribir los criterios de admisión irrazonables o desproporcionados, pues afectan de manera directa el derecho a la educación de los menores [en consecuencia] frente a una negación de la entidad educativa de admitir a un escolar cabe analizar si las razones que la sustentan son conformes con la Constitución (STC 4646-2007-PA/TC, F.J 18).

En relación con la permanencia en el sistema educativo y el respeto de la dignidad del educando, el TC ha sostenido que éste no pueda ser separado del centro educativo por motivos que no guarden relación con el principio de proporcionalidad; aunque esta garantía no exime al estudiante de cumplir un régimen disciplinario al interior de la escuela que sea conforme a dicho principio, y por ende prohíbe todo tipo de tortura o de trato cruel, inhumando o degradante al interior de las escuelas (STC 4646-2007-PA/TC, FF.JJ 19 - 20). El derecho a permanecer en el sistema educativo tampoco exonera a los estudiantes de cumplir con sus obligaciones académicas y administrativa, puesto que las exigencias académica cumplen con dos finalidades,

por un lado, es competencia de toda entidad educativa establecer márgenes mínimos razonables para procurar la mejor formación académica posible ... por otro lado, forma parte de los deberes académicos del educando aprobar satisfactoriamente los cursos que se le imparte, pues ello implica la adquisición satisfactoria de nuevas capacidades técnicas o profesionales (STC 01351- 2012-PA) TC, FF.JJ 6 y 8).

De igual modo, acerca de la calidad de la educación, el TC ha señalado que ésta se encuentra referida tanto a asegurar el desarrollo cognitivo del educando cuando a la promoción de actitudes 
y valores de carácter cívico. Precisamente, en atención a este contenido del derecho a la educación y a la participación privada en su realización, la Constitución establece la obligación del Estado de supervisar la calidad de la educación, la de regular y promover la carrera magisterial (STC 4646-2007PA/TCFF.JJ 22-23).

Asimismo, como se señaló antes, el TC, al amparo de la Cuarta Disposición Final y Transitoria de la Constitución, también ha considerado la normativa internacional prevista en el Pacto Internacional de Derechos Económicos, Sociales y Culturales y el Pacto de San Salvador para precisar el contenido del derecho a la educación. En esa línea, ha acogido en su jurisprudencia los criterios desarrollados por el Comité de Derechos Económicos, Sociales y Culturales sobre los elementos esenciales del proceso educativo. En particular, el TC ha indicado que la educación en todos sus niveles y formas debe tener cuatro características fundamentales que se encuentran interrelacionadas; a la sazón: disponibilidad, accesibilidad (no discriminación, accesibilidad material y accesibilidad económica), aceptabilidad y; adaptabilidad (STC 0091-2005-PA/TC, F.J 6; STC 4232-2004-AA/TC, F.J 16; STC 4646-2007-PA/TC F.J 32). De esta manera, el TC ha puesto en evidencia la articulación que debe darse entre las normas constitucionales y los tratados internacionales sobre derechos humanos, así como con los pronunciamientos de los órganos internacionales en materia de derechos fundamentales, pues los diferentes dispositivos constitucional que configuran el régimen constitucional de la educación deben ser leídos e interpretados en conjunto con los tratados internacionales sobre derechos humanos en atención a lo establecido en el artículo $55^{\circ}$ y la Cuarta Disposición Final y Transitoria de la Constitución que establecen que los tratados internacionales forman parte del derecho nacional, y que las normas constitucionales que reconocen derechos y libertades se interpretan de acuerdo con la Declaración Universal de los Derechos Humanos y los tratados internacionales ratificados por el Perú.

De acuerdo, a la Declaración Universal de Derechos Humanos

Toda persona tiene derecho a la educación. La educación debe ser gratuita, al menos en lo concerniente a la instrucción elemental y fundamental. La instrucción elemental será obligatoria. La instrucción técnica y profesional habrá de ser generalizada; el acceso a los estudios superiores será igual para todos, en función de los méritos respectivos.

A partir, de esta disposición, el Pacto Internacional de Derechos Económicos Sociales y Culturales y, posteriormente, el Pacto de San Salvador reconocen el derecho a la educación como un derecho humano de carácter universal, del que deben gozar, sin discriminación alguna, todas las personas, y cuya realización plena se encuentra sujeta al principio de progresividad. ${ }^{9}$ Vale decir, reconoce la dimensión subjetiva del derecho a la educación.

\footnotetext{
9 Sobre el principio de progresividad, el artículo 2.1 del Pacto señala que: "Cada uno de los Estados Partes del presente Pacto se compromete a adoptar medidas, tanto por separado como mediante la asistencia y la cooperación internacional, especialmente económicas y técnicas, hasta el máximo de los recursos de que disponga, para lograr progresivamente, por todos los medios apropiados, inclusive en particular la adopción de medidas legislativas, la plena efectividad de los derechos aquí reconocidos. .."
} 
El Pacto Internacional de Derechos Económicos, Sociales y Culturales (artículo 13²) señala que los Estados partes reconocen el derecho de toda persona a la educación y precisa que la educación debe orientarse hacia el pleno desarrollo de la personalidad humana y del sentido de su dignidad, y debe fortalecer el respeto por los derechos humanos y las libertades fundamentales. De igual modo, indica que la educación debe capacitar a todas las personas para participar efectivamente en una sociedad libre, debe favorecer la comprensión, la tolerancia y la amistad entre todas las naciones y entre todos los grupos raciales, étnicos o religiosos. Con esa finalidad, precisa que la enseñanza primara debe ser obligatoria y asequible a todos gratuitamente, mientras que la enseñanza secundaria debe ser generalizada y hacerse accesible a todos, por lo que la gratuidad debe implementarse progresivamente. En el caso de la educación o enseñanza superior señala que debe ser igualmente accesible a todos, sobre la base de la capacidad de cada uno, pero debe apuntarse a la implantación progresiva de su gratuidad. Finalmente, este tratado reconoce también que la libertad de los padres de escoger la educación y escuelas para sus hijos forma parte del derecho a la educación, de manera que reciban la educación religiosa o moral que esté de acuerdo con sus propias convicciones.

A su turno, el artículo $13^{\circ}$ del Protocolo Adicional a la Convención Americana sobre Derechos Humanos en materia de derechos económicos, sociales reconoce que toda persona tiene derecho a la educación y que ésta debe orientarse a lograr el pleno desarrollo de la personalidad humana y del sentido de su dignidad. En esa medida, indica también que la educación deberá fortalecer el respeto por los derechos humanos, el pluralismo ideológico, las libertades fundamentales, la justicia y la paz; debiendo orientarse a capacitar a todas las personas para participar efectivamente en una sociedad democrática y pluralista, así como darle los medios para lograr una subsistencia digna y favorecer la comprensión, la tolerancia entre las naciones y todos los grupos raciales étnicos o religioso. Para lograr el pleno ejercicio del derecho a la educación, este tratado internacional también dispone que la enseñanza primaria debe ser obligatoria y asequible a todos gratuitamente, mientras que progresivamente debe asegurarse el acceso gratuito y general a la enseñanza secundaria, así como a la enseñanza superior en base a la capacidad de cada una de las personas. Asimismo, establece que la legislación interna de los Estados debe reconocer a los padres el derecho a escoger el tipo de educación que quieran darles a sus hijos, siempre que contradiga los fines previsto para la educación en el tratado internacional.

Asimismo, ambos tratados internacionales establecen que la plena realización del derecho a la educación se encuentra sujeta el principio de progresividad debido a que la "plena efectividad de todos los derechos económicos, sociales y culturales en general no podrá lograrse en un breve

\footnotetext{
En esa misma línea, el Protocolo Adicional a la Convención Americana sobre Derechos Humanos en materia de Derechos Económicos, Sociales y Culturales señala: "Artículo $1^{\circ}$ Los Estados Partes del presente Protocolo Adicional a la Convención Americana sobre Derechos Humanos se comprometen a adoptar las medidas necesarias tanto de orden interno como mediante cooperación entre los Estados, especialmente económica y técnica, hasta el máximo de los recursos disponibles y tomando en cuenta su grado de desarrollo, a fin de lograr progresivamente, y de conformidad con la legislación interna, la plena efectividad de los derechos que se reconocen en el presente Protocolo." (el subrayado en nuestro).
} 
período de tiempo." (Comité de Derechos Económicos, Sociales y Culturales, 1990, párrafo 9). Este principio impone a los Estados la obligación de adoptar, en un plazo razonable, medidas deliberadas, concretas y orientadas a lograr la plena satisfacción de los derechos sociales, como el derecho a la educación; exigiendo que toda medida de carácter regresivo respecto a la satisfacción de los derechos sociales sea adoptada luego de una adecuada evaluación y que su justificación esté relacionada con la protección de la totalidad de los derechos reconocidos en el tratados internacional, así como en el contexto del máximo aprovechamiento de los recursos de que disponga cada Estado (Comité de Derechos Económicos, Sociales y Culturales, 1990, párrafos 3 y 9).

No obstante, el carácter progresivo de las obligaciones que se derivan de los derechos sociales, no libera a los Estados del deber de cumplir con los niveles mínimos de satisfacción de estos derechos; porque existen ciertos niveles mínimos de cada derecho que serán exigibles de forma inmediata a los Estado y no estando sujetas el principios de progresividad (Comité de Derechos Económicos, Sociales y Culturales, 1990, párrafo 10). Así, por ejemplo, el nivel mínimo de satisfacción del derecho a la educación, como lo es acceder al sistema educativo sin discriminación alguna, no debe entenderse sujeto al principio de progresividad.

Las normas de los tratados internacionales sobre derechos humanos complementan las normas constitucionales y contribuyen a identificar el contenido del derecho a la educación; conformando un bloque de protección con las interpretaciones que, sobre el Pacto Internacional del Derechos Económicos, Sociales y Culturales, realice el Comité de Derechos Económicos, Sociales y Culturales, ${ }^{10}$ como órgano encargado de supervisar la aplicación del Pacto. En particular, deben destacarse sus observaciones generales en las que definen y precisa el alcance de las obligaciones de los Estados que han ratificado el mencionado tratado internacional.

\subsection{El aporte de las normas internacionales sobre derechos humanos y el Comité de Derechos Económicos, Sociales y Culturales}

Sobre el derecho fundamental a la educación, el mencionado Comité ha señalado que son cuatro los elementos que deben de estar presentes en el proceso educativo para satisfacerlo, en particular: la disponibilidad; la accesibilidad; la aceptabilidad y; la adaptabilidad (Comité de Derechos Económicos, Sociales y Culturales, 1990, párrafos 6-7). Respecto al elemento disponibilidad el Comité señala que deben existir las instituciones y programas de enseñanza en cantidad suficiente respecto al número de población y extensión territorial de cada Estado, así como que los centros educativos estén dotados de docentes calificados, de material educativo de calidad y de servicios sanitarios. De ahí que, con relación a la disponibilidad, se vulneren los elementos mínimos del derecho a la

\footnotetext{
10 Economic and Social Council. Resolution 1985/17. Review of the composition, organization and administrative arrangements of the Sessional Working Group of Governmental Experts on the Implementation of the International Covenant on Economic, Social and Cultural Rights. 22nd plenary meeting 28 May 1985.
} 
educación si, por ejemplo, se cierran de forma arbitraria escuelas privadas, o no se dota a las escuelas de infraestructura educativa adecuada, o se impide que se creen escuelas privadas en zonas donde no existe (Comité de Derechos Económicos, Sociales y Culturales, 1990, párrafo 50).

Con relación a la accesibilidad, el Comité señala que exige que las instituciones y los programas de enseñanza sean accesibles a todos, sin discriminación alguna; en esa medida, este elemento tiene tres dimensiones: el respeto al mandato de no discriminación, en especial respecto a los grupos más vulnerable; la accesibilidad material en términos geográficos o de tecnología; y la accesibilidad económica referida a la obligatoriedad y la gratuidad de la enseñanza. En esa línea, los elementos mínimos de esta aspecto de la educación se afectaría si, por ejemplo, el Estado no impide que los padres dejen de enviar a las niñas a la escuela, o si el Estado impusiera la obligación de llevar un uniforme costoso para asistir a los centros educativos, o si se impusieran tasas de matrícula u otros pagos que resulten manifiestamente excesivos para la realidad (Comité de Derechos Económicos, Sociales y Culturales, 1990, párrafo 50).

El tercer elemento del derecho a la educación, según el Comité de Derechos Económicos, Sociales y Culturales, es la aceptabilidad, la misma que demanda que los programas de estudio y los métodos de enseñanza sean pertinentes, adecuados culturalmente y de buena calidad. Asimismo, el diseño de dichos programas debe obedecer a los objetivos y fines de la educación previstos en la Constitución y el Pacto Internacional de Derechos Económicos, Sociales y Culturales. En consecuencia, se vulnerarían los elementos mínimos de esta dimensión del derecho a la educación si el Estados impusiera un sistema educativo en lengua distinta a la predominante en determinada zona del país o sin respetar a las minorías indígenas, o si los contenidos de los programas educativos no tuvieran como referente el medio y la cultura de la comunidad, o si la escuela promoviera prácticas que denoten intolerancia a la diversidad cultural.

Finalmente, respecto al elemento adaptabilidad, la satisfacción del derecho a la educación exige que la enseñanza - planes y programas de estudio - tenga la flexibilidad necesaria para adaptarse a las necesidades de comunidades y sociedades que cambian o se transforman, y respondan a las necesidades de alumnos y alumnas que provengan de contexto culturales o sociales variados. Los elementos mínimos de la adaptabilidad se verían afectados si, por ejemplo, no se actualizarán periódicamente los planes y programas educativos, o si no se implementarán programas educativos en los centros de readaptación de menores, o si no se adoptan planes y programas de estudio con carácter inclusivo para niños y niñas con discapacidad. La educación inclusiva, en esa medida, forma parte del contenido protegido del derecho a la educación (Defensoría del Pueblo, 2007, pp. 24-30).

El Comité de Derechos Económicos, Sociales y Culturales ha señalado que "Si bien el Pacto dispone su puesta en práctica gradual y reconoce las restricciones debidas a las limitaciones de los recursos disponibles, impone también a los Estados Partes diversas obligaciones con efecto inmediato" (1990, párrafo 43). Vale decir, establece que los Estados desarrollen actividades regulares y continuas para satisfacer los distintos elementos mínimos del derecho a la educación, debiendo utilizar hasta el 
máximo de los recursos a su disposición. Asimismo, si un Estado adopta medidas regresivas respecto de los niveles de realización del derecho a la educación, debe demostrar que la decisión se justifica en relación con la totalidad de los derechos fundamentales y en el contexto de aprovechamiento máximo de los recursos disponibles (Comité de Derechos Económicos, Sociales y Culturales, 1990, párrafo 45).

Con el reconocimiento del derecho a la educación el Estado no sólo está obligado a cumplir con prestaciones, sino que, como sucede con otros derechos humanos, del derecho a la educación se derivan tres tipos de obligaciones para los Estados; a la sazón, las obligaciones de respetar, proteger y cumplir - garantizar o promover - (Abramovich \& Courtis, 2002, pp. 29-31). La obligación de respecto exige que los Estados partes eviten obstaculizar o impedir el disfrute del derecho a la educación; mientras que obligación de proteger, impone a los Estados Partes la adopción de medidas que eviten que el derecho a la educación sea obstaculizado por terceros. Finalmente, la obligación de dar cumplimiento (facilitar) exige que los Estados adopten medidas positivas que permitan a individuos y comunidades disfrutar del derecho a la educación y les presten asistencia (Comité de Derechos Económicos, Sociales y Culturales, 1999, párrafos 46-47).

Lo sostenido por el Comité de Derechos Económicos, Sociales y Culturales constituye pauta interpretativa de las normas constitucionales que reconocen el derecho a la educación, particularmente contribuye a identificar su dimensión subjetiva, aunque sin desatender la dimensión institucional. En esa medida, deben orientar la labor que realice el legislador respecto del derecho a la educación, que se configura también como un derecho fundamental de configuración legal, no sólo porque la mayoría de las normas constitucionales que lo regulan -artículos $13^{\circ}, 14^{\circ}, 15^{\circ}, 16^{\circ}$ y $17^{\circ}$ - están formuladas como normas principios, sino porque el propio Texto Constitucional, en más de una oportunidad, ha establecido que una ley desarrollará el contenido de ciertos de sus dispositivos (Borowski, 2003, pp. 47-53).

La configuración legal de un derecho fundamental no debe entenderse como una limitación del derecho a la educación porque la participación del legislador en la configuración de los derechos fundamentales, tanto de los derechos de libertad cuanto de los derechos sociales, debe ser considerada normal e incluso necesaria a efectos de garantizar su eficacia en tanto se articulan en torno a los derechos fundamentales garantías específicas, imponiendo obligaciones concretas a las entidades el Estado (Ferrajoli, 2001, pp. 59-65). En efecto, la reserva legal para el desarrollo de los derechos fundamentales no debe ser entendida como disminución de su fuerza normativa, porque ésta se deriva del sólo reconocimiento del derecho en el Texto Constitucional y, ciertamente, en los tratados internacionales, tal como sucede con el derecho a la educación. En esa medida, la reserva de ley, debe ser considerada como una garantía que promociona y puede tornar más operativo el ejercicio de los derechos fundamentales, mas no como un obstáculo que difiera en el tiempo la eficacia normativa de los mismos (Prieto Sanchís, 1990, p. 118). 
No obstante, no sólo el legislador se encuentra vinculado al desarrollo interpretativo que ha realizado el Comité de Derechos Económicos, Sociales y Culturales sobre el derecho a la educación también lo está el TC, que debe atender lo dispuesto tanto por los tratados internacionales cuanto por las interpretaciones que realicen los órganos internacionales encargados de la supervisión del cumplimiento de dichos tratados, que forman parte del derecho interno. De ahí que en varias de sus sentencias el TC, siguiendo los desarrollos del Comité de Derechos Económicos Sociales y Culturales, por ejemplo, ha indicado que la educación en todos sus niveles y formas debe tener cuatro características fundamentales que se encuentran interrelacionadas; a la sazón: disponibilidad, accesibilidad, aceptabilidad y; adaptabilidad (STC 0091-2005-PA/TC, F.J 6; STC 4232-2004-AA/TC, F.J 16; STC 4646-2007-PA/TC, F.J 32).

\subsection{La naturaleza binaria de la educación: derecho fundamental y servicio público}

Finalmente, otro aspecto a destacar sobre el desarrollo que ha realizado el TC acerca del derecho a la educación es la doble naturaleza, o "carácter binario" que ha atribuido al mismo. En efecto, el TC ha señalado que la educación no es sólo un derecho fundamental sino que se configura también como un servicio público, ${ }^{11}$ "en la medida que se trata de una prestación pública que explicita una de las funciones-fines del Estado, de ejecución per se o por terceros bajo la fiscalización estatal. Por ende, el Estado tiene la obligación de garantizar la continuidad de los servicios" (STC 4232-2004-AA/ TC, F.J 11; STC 4646-2007-PA/TC, F.J 25; STC 00025-2007-PI/TC, F. J. 22), así como la ampliación y mejoramiento progresivo de la cobertura y calidad de estos servicios. Esta particularidad también ha sido incorporada en el artículo $4^{\circ}$ de la Ley $N^{\circ} 28044$, Ley General de Educación, ${ }^{12}$ que forma parte del desarrollo legislativo del derecho fundamental a la educación.

Adicionalmente, el TC ha convalidado el carácter de servicio público esencial atribuido a la educación en la Ley No 28988, Ley que declara a la educación básica regular como servicio público esencial. ${ }^{13}$ En esa línea, la educación, como servicio público esencial, se considera una razón legítima para limitar el derecho de huelga de los profesores; por ende, el ejercicio de este derecho no podría implicar el cese total de actividades vinculadas al servicio educativo. Así, si la huelga fuera de larga duración, se "podría requerirse el establecimiento de servicios mínimos en consulta plena con los interlocutores sociales" (STC 00025-2007-PI/TC, F. J. 33). Sin embargo, el TC omite indicar cuáles serían los criterios para fijar los servicios mínimos en materia de educación, o cuáles son esos servi-

\footnotetext{
11 Para el TC los elementos que identifican a un servicio público son: (i) la naturaleza esencial para la comunidad que tiene el servicio; (ii) la necesaria continuidad de su prestación en el tiempo; (iii) la regularidad del servicio; (iv) el deber de mantener un estándar mínimo de calidad y; (v) la necesidad de que su acceso se dé en condiciones de igualdad. Asimismo, para el TC la educación reúne todos esos elementos y, por ende, debe ser considerada también un servicio público (STC N 0034-2004-AI/ TC de 15 de febrero de 2005, F.J. 40).

12 Publicada en el Diario Oficial El Peruano el 29 de julio de 2003.

13 Publicada en el Diario Oficial El Peruano el 21 de marzo de 2007. El carácter de servicio público esencial también se afirma en la Ley N ${ }^{\circ}$ 29062, Ley que modifica la Ley del Profesorado en lo referido a la carrera pública magisterial, publicada el 12 de julio de 2007.
} 
cios mínimos que correspondería seguir prestando durante la vigencia de la huelga; tal como sí han sido desarrollado respecto del servicio público de salud en el que no se interrumpen los servicios que pueda poner en riesgo la vida, la seguridad o la salud de las personas.

\section{Reflexiones finales}

Resulta importante reconocer el esfuerzo interpretativo desplegado por el TC en relación con la protección del derecho a la educación, dado que ha permitido en diversos casos proteger la dimensión subjetiva de este derecho fundamental que, en los dispositivos constitucionales fue formulado en clave de mandatos objetivos. El empleo de la tesis sobre el doble carácter de los derechos fundamentales; en particular, evidenciar cómo a partir de la interpretación de complejos normativos objetivos, es posible derivar las principales posiciones subjetivas protegidas por el derecho a la educación constituye un ejercicio de concretización que da cuenta la estrecha y recíproca relación que existe entre ambas dimensiones de los derechos fundamentales. De manera que solo es posible entender correctamente el contenido de un derecho fundamental si a ambos aspectos se llega deduciendo del uno del otro (Häberle, 2003, p.99).

Particular relevancia tiene esta construcción dogmática para la protección de los derechos sociales reconocidos en la Constitución peruana, debido a que el acento de los dispositivos constitucionales que los garantizan está puesto en la dimensión objetiva o institucional, como se ha podido apreciar respecto al derecho a la educación. Esto no significa que la dimensión objetiva de los derechos fundamentales absorba el contenido subjetivo, sino que se suman y condicionan mutuamente, como una unidad (Böckenförde, 1993, p. 117). Así, la realización de la dimensión subjetiva de los derechos fundamentales requiere de la satisfacción de la dimensión objetiva, en particular, de los marcos normativos y funcionales que se adoptan para dar entidad de los mandatos objetivos de protección de derechos.

Asimismo, es importante concluir destacando cómo la alineación y la articulación cada vez más intensa entre las normas constitucionales y los desarrollos del Derecho Internacional de los derechos humanos, a partir de la aplicación de cláusulas como la Cuarta Disposición Final y Transitoria de la Constitución, permiten arribar a posiciones garantistas de los derechos sociales, como el derecho a la educación. De manera que la identificación de posiciones iusfundamentales y obligaciones concretas que deben sustentar las política públicas educativas que permitan remontar los déficit desempeño que presentan los estudiantes en el Perú, así como avanzar en el logro del Objetivo 4 de los Objetivo de Desarrollo Sostenible.

Finalmente, dada la importancia del derecho a la educación como presupuesto para garantizar la plena realización de los seres humanos y el ejercicio de otros derechos fundamentales, sería oportuno que, en un futuro ejercicio de reforma constitucional, puede incluirse un dispositivo que recoja su dimensión subjetiva en el texto constitucional. 


\section{Bibliografía}

Abad Yupanqui, S. (2008). El proceso constitucional de amparo (2a ed.). Lima, Gaceta Jurídica.

Abramovich, V., \& Courtis C. 2002. Los derechos sociales como derechos exigibles. Madrid: Trotta.

Alexy, R. (1993). Teoría de los derechos fundamentales. Madrid: CEC.

Alexy, R. (2003). Tres escritos sobre los derechos fundamentales y la teoría de los principios. Serie de teoría jurídica y filosofía del Derecho, N²8, Bógota, Universidad Externado de Colombia.

Alvites, E. (2004). La participación de la jurisdicción constitucional en la defensa del constitucionalismo social: a propósito de la protección jurisdiccional de los derechos sociales por el Tribunal Constitucional peruano (Tesis doctoral, Universidad de Alicante). Disponible en: http://rua.ua.es/dspace/handle $/ 10045 / 174 /$ browse? type $=$ author\&order $=$ ASC\&rpp $=75 \&$ value $=$ Alvites + Alvites $\% 2 C+$ Elena + Cecilia

Añon Roig, M. J. (1994). Necesidades y derechos. Un ensayo de fundamentación. Madrid: CEPC.

Arango, R. (2001). Protección Nacional e internacional de los derechos humanos sociales. En VV. AA. Ciudadanía y derechos humanos sociales. Medellín, Instituto Sindical de Cooperación al Desarrollo - Junta de Andalucía.

Baldassarre, A. (2004). Los derechos sociales. Serie de Teoría jurídica y filosofía del Derecho № 20, Bogotá, Universidad Externado de Colombia.

Borowski, M. (2003). La estructura de los derechos fundamentales. Serie de Teoría Jurídica y Filosofía del Derecho №25, Universidad Externado de Colombia.

Böckenförde, E. W. Escritos sobre derechos fundamentales. Nomos, 1993.

Cascajo Castro, J. L. (1988). La tutela constitucional de los derechos sociales. Madrid: CEPC.

Castillo Córdova, L. (2004). El principio de libertad en el sistema educativo. Piura: Universidad de Piura - Ara Editores.

Castillo Córdova, L. (2005). Los Derechos Constitucionales. Elementos para una teoría general. Lima: Palestra.

Comisión de Derechos Humanos (1999, enero 13). E/CN.4/1999/49 Informe Preliminar de la Relatora Especial sobre el derecho a la educación, $55^{\circ}$ Período de Sesiones.

Comité de Derechos Económicos, Sociales y Culturales (1990, diciembre 8). Observación General No 13, El derecho a la educación (artículo 13 del Pacto).

Defensoría del Pueblo (2008). Informe Defensorial No 131. Gratuidad en las escuelas públicas. Un compromiso pendiente. Lima.

Defensoría del Pueblo (2007). Informe Defensorial No 127. Educación Inclusiva: Educación para todos., Lima. 
Ferrajoli, L. (2001). Derechos y garantías. La ley de más débil (2a ed.). Madrid: Trotta.

García Pelayo, M. (1994). Las transformaciones del Estado contemporáneo (8a reimpresión). Madrid: Alianza Editorial.

Häberle, P. (2003a). El Estado constitucional. Lima, UNAM-Fondo Editorial de la PUCP.

Häberle, P. (1991) La Garantía constitucional de los derechos fundamentales en Alemania. En A. López Pina (Director), La Garantía constitucional de los derechos fundamentales. Alemania, España, Francia e Italia. Madrid, Civitas - Servicio de Publicaciones de la Universidad Complutense de Madrid.

Häberle, P. (2003b). La garantía del contenido esencial de los derechos fundamentales en la Ley Fundamental de Bonn. Madrid: Dykinson.

Häberle, P. (2002). Pluralismo y constitución. Estudios de teoría constitucional de la sociedad abierta. Madrid, Tecnos.

Kelsen, H. (1986). Teoría pura del Derecho. México: UNAM.

Kweitel, J., \& Ceriani, P. (2006). El derecho a la educación. En V. Abramovich, M. J. Añon, \& C. Courtis. Derecho sociales. Instrucciones de uso. México: Fontanamara.

Landa Arroyo, C. (2017). Los derechos fundamentales. Colección lo esencial del Derecho 2. Lima: Fondo Editorial de la Pontificia Universidad Católica del Perú.

Langford, M. (2013). Teoría y jurisprudencia de los derechos sociales: tendencias emergentes en el derecho internacional y comparado. Bogotá, Siglo del Hombre - Universidad de los Andes.

Laporta, F. (1987). Sobre el concepto de Derechos Humanos. Doxa, (4).

Martínez de Pisón, J. (2003). El derecho a la educación y la libertad de enseñanza. Cuadernos "Bartolomé de las Casas" No 27. Madrid, Dykinson - Universidad Carlos III de Madrid.

Ministerio de Educación del Perú (2017a). ¿Cuánto aprenden nuestros estudiantes? Resultados de la ECE 2016. Disponible en: http://umc.minedu.gob.pe/wp-content/uploads/2017/04/Resultados-Nacionales-2016.pdf

Ministerio de Educación del Perú (2017b). Edudatos, № 28. Objetivos de Desarrollo Sostenible (ODS): Aproximación al Objetivo 4. Disponible en: http://escale.minedu.gob.pe/c/document library/get_file?uuid=187e3719-3b8b-4eab-af88-20c9e1e62e96\&groupId=10156

Ministerio de Educación del Perú (2017c). Resultados de la Evaluación Censal de Estudiantes ECE 2016. Disponible en: http://umc.minedu.gob.pe/wp-content/uploads/2017/04/ECE-2016-presentaci\%C3\%B3n-de-resultados-web.pdf

Nery da Silva, R. \& Garcia Masson, D. (2015). El Derecho social a la educación en la política pública de Brasil - El Plan de Desarrollo de la Educación (PDE). En Strapazzon, Carlos Luiz (Coord.). Barceló $i$ Serramalera y Barcelona, Atelier.

Prieto Sanchís, L. (1990). Estudios sobre derechos fundamentales. Madrid, Debate. 
Programa de Naciones Unidas para el Desarrollo (2015). Folleto sobre los Objetivos de Desarrollo Sostenible. Disponible en: http://www.undp.org/content/undp/es/home/librarypage/corporate/ sustainable-development-goals-booklet.html

Organización de las Naciones Unidas para la Educación, la Ciencia y la Cultura (2017). Desglosar el Objetivo de Desarrollo Sostenible 4 Educación 2030. Disponible en: http://unesdoc.unesco.org/ images/0024/002463/246300S.pdf

Sentencia correspondiente al Expediente Nº0025-2007-PI/TC de 19 de setiembre de 2008.

Sentencia correspondiente al Expediente No 0052-2004-AA/TC de 1 de setiembre de 2004.

Sentencia correspondiente al Expediente Nº034-2004-AI/TC de 15 de febrero de 2005.

Sentencia correspondiente al Expediente No 0091-2005-PA/TC de 18 de febrero de 2005.

Sentencia correspondiente al Expediente No 01351-2012-PA/TC de 8 de setiembre de 2015.

Sentencia correspondiente al Expediente N 01423-2013-PA/TC de 9 de diciembre de 2015.

Sentencia correspondiente al Expediente Nº4587-2004-AA/TC de 29 de noviembre de 2005.

Sentencia correspondiente al Expediente N 10034-2005-PA/TC de 26 de marzo de 2007.

Sentencia correspondiente al Expediente N 1391-2007-PA/TC de 13 de noviembre de 2007.

Sentencia correspondiente al Expediente N 1417-2005-AA-TC de 8 de julio de 2005.

Sentencia correspondiente al Expediente N 1757-2007-PA/TC de 30 de noviembre de 2009.

Sentencia correspondiente al Expediente N 3330-2004-AA/TC de 11 de julio de 2005.

Sentencia correspondiente al Expediente N 4232-2004-AA/TC de 03 de marzo de 2005.

Sentencia correspondiente al Expediente No 4232-2004-AA/TC de 19 de julio de 2006.

Sentencia correspondiente al Expediente N4646-2007-PA/TC de 17 de octubre de 2007.

Tribunal Constitucional Peruano. Disponible en: http://www.tc.gob.pe/tc/public/resolucion/ pubwebdia/ultimo/total

Data de submissão: 28 de novembro de 2017 Aceito em: 08 de dezembro de 2017 
